\title{
СОВРЕМЕННЫЕ ИННОВАЦИОННЫЕ ПОДХОДЫ К РАЗВИТИЮ ГОСТИНИЧНОГО БИЗНЕСА В МИРЕ И ПРАКТИКЕ КАЗАХСТАНА
}

\author{
PhD, associate professor Gyuzel Ishkinina, Head of the Department of academic policy \\ student Anastassia Shvedchikova,
}

Kazakhstan, Ust-Kamenogorsk, Kazakh-American Free University;

DOI: https://doi.org/10.31435/rsglobal_ijite/30062019/6529

\section{ARTICLE INFO}

Received 13 April 2019

Accepted 19 June 2019

Published 30 June 2019

\section{KEYWORDS}

hotel business, innovative approaches to development of hotel, automated management systems, hotel, tourists

\begin{abstract}
The article provides an analysis of the development of hotel in Kazakhstan for 2015-2018. The study is based on statistical information about results of the work hotels according to data from Statistics Committee Ministry of National Economy Republic of Kazakhstan. Moreover, in this article is studied modern innovative approaches to development of hotel in the world, to assess their implementation into practice Kazakh hotels. The results of research confirm the improvement of developing of hotel in Kazakhstan for 2015-2018 and slow implementation innovative approaches to development of Kazakh hotels.
\end{abstract}

Citation: Gyuzel Ishkinina, Anastassia Shvedchikova. (2019) Sovremennye Innovacionnye Podhody k Razvitiyu Gostinichnogo Biznesa v Mire i Praktike Kazahstana. International Journal of Innovative Technologies in Economy. 4(24). doi: 10.31435/rsglobal_ijite/30062019/6529

Copyright: (C) 2019 Gyuzel Ishkinina, Anastassia Shvedchikova. This is an open-access article distributed under the terms of the Creative Commons Attribution License (CC BY). The use, distribution or reproduction in other forums is permitted, provided the original author(s) or licensor are credited and that the original publication in this journal is cited, in accordance with accepted academic practice. No use, distribution or reproduction is permitted which does not comply with these terms.

Введение. Гостиничный бизнес является важным звеном в сфере туризма. Технологии в гостиничной сфере сегодня развиваются молниеносно. Стараясь обогнать конкурентов, гостиницы по всему миру все больше придумывают способы, как угодить клиенту.

Для эффективного развития гостиничного бизнеса менеджерами проводится поиск новых методов качественного обслуживания, охраны номеров и предоставления новых услуг для потребителей, которые сегодня внедряются в практику отелей зарубежных стран.

Инновации являются одним из путей для улучшения качества производства и быстрого качественного предоставления услуг в сфере гостиничного бизнеса. В большинстве современных гостиниц, есть онлайн бронирование и свои сайты. Отрадно, что сайты переведены на иностранные языки, тем самым есть возможность людям за рубежом получить информацию о месте, где они желают отдохнуть.

Следует отметить, что инновации в гостиничном бизнесе связаны непосредственно с развитием Интернета. Интернет позволяет в значительной степени повысить оперативность и качество связи, снизить затраты на коммуникации и командировки, расширить географию деятельности, круг клиентов и партнеров. Подобные инновации, связанные с интернетом, быстро набирают популярность у владельцев гостиниц, потому что выгода от их использования уже проверена временем.

Разработка и внедрение автоматизированных систем управления происходит в основном в крупных гостиницах. Наиболее популярными на этом рынке являются западные системы - «Micros Fidelio», «Lodging Touch LIBICA», Hospitality Enterprise Resource Planning «Cenium», Epitome PMS, Amadeus PMS, OPERA. На российском рынке известны такие как "Nimeta», «Эдельвейс», «Отель», «KEI Hotel», «UCS Shelter», соответствующие модули корпоративных систем Галактика и Парус.

Типичная структура автоматизированной системы управления гостиницей представлена ниже на рис.1. 


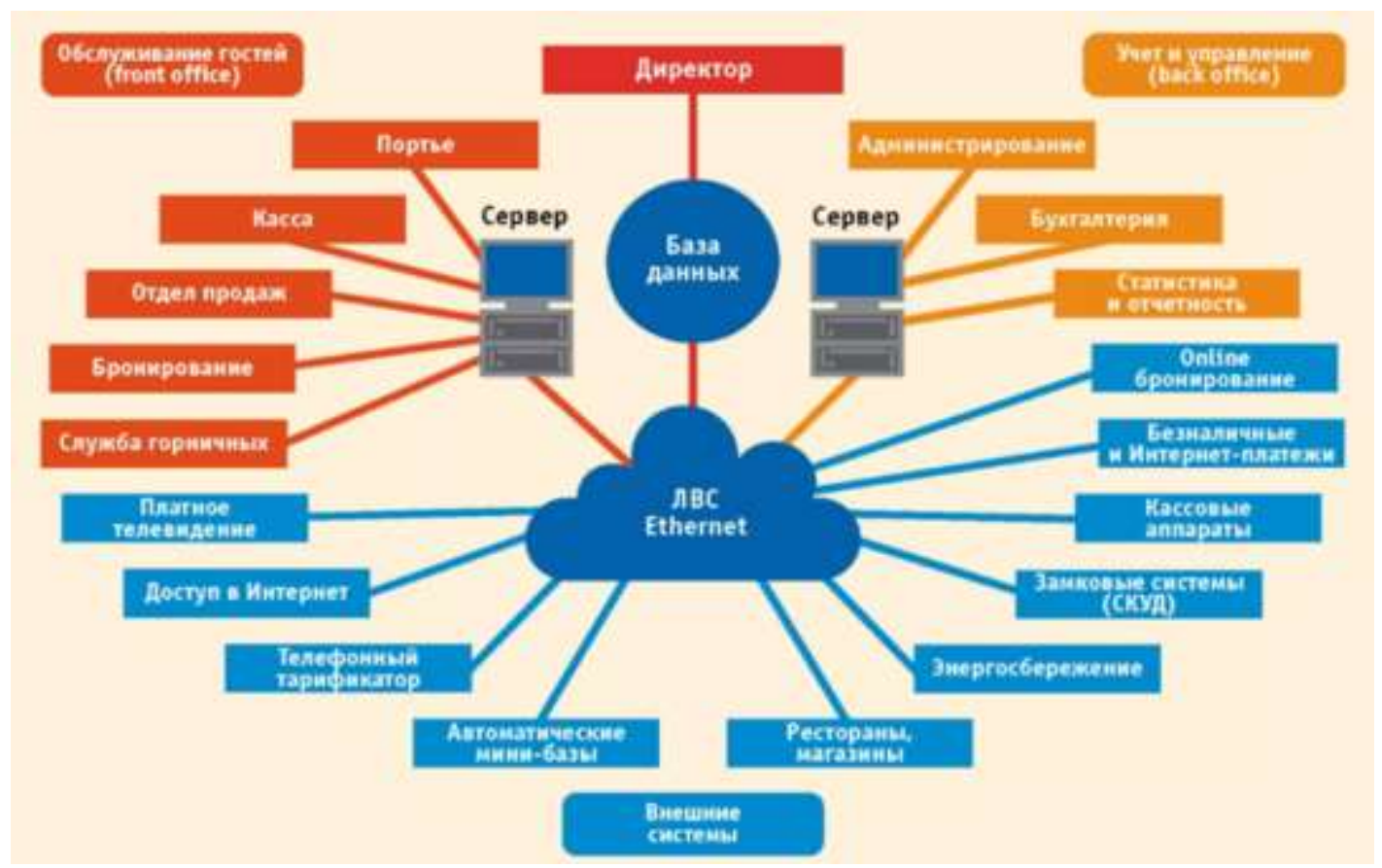

Рис. 1. Структура автоматизированной системы управления гостиницей [2].

Основными требованиями гостиниц к автоматизированным системам управления являются:

- мощные функциональные возможности управления тарифной политикой, номерным фондом и обслуживанием гостей;

- использование всех существующих каналов продаж гостиничных услуг (Интернет, GDS (Global Distribution System), call-центры);

- широкие возможности финансового контроля и аудита;

- управление центрами прибыли (номерной фонд, рестораны, бары, фитнес, прачечная, бизнес центр);

- организация проведения мероприятий (конгрессов, банкетов, конференций);

- наличие интерфейсов с системами автоматической авторизации кредитных карт;

- наличие интерфейсов с периферийными системами (интерактивное ТВ, телефония, замки, минибары, управление энергетикой);

- возможность реализации программ постоянных гостей и участия в бонусных программах авиакомпаний;

- расчет причитающихся турагентствам комиссионных платежей;

- возможность осуществлять групповое бронирование с гибкой системой индивидуальных расчетов с гостями;

- надежность и отказоустойчивость;

- сопровождение и круглосуточная поддержка;

- постоянное развитие систем в соответствии с требованиями рынка.

К сожалению, во многих гостиницах без «звезд» всю информацию о постояльцах до сих пор заносят в обычный журнал вручную.

Повысить эффективность системы управления гостиничным комплексом помогают программы, приложения для компьютеров. К специальной сети, содержащей все необходимые данные, подключают каждого сотрудника. Это позволяет получить доступ к информации тогда, когда возникает надобность, своевременно отреагировать на любые изменения, касающиеся продаж, бронирования.

Кроме того, известные гостиничные корпорации вслед за авиакомпаниями начали использование компьютерных гостиничных систем, как для внутреннего управления, так и создания собственных транснациональных компьютерных систем бронирования и резервирования мест. Например, корпорация "Starwood Hotels \& Resorts" предлагает своим гостям стать участником программы «Starwood Preferred Guest (SPG) - Программа Привилегированных Гостей Старвуда», которая является самой популярной программой лояльности среди гостиничных сетей. Члены 
программы получают баллы и дополнительные услуги в отелях сетей Westin, Sheraton, St. Regis, Luxury Collection, Hotels и Four Points в более 740 отелях в 80 странах.

С целью удовлетворения потребностей деловых людей в крупнейших деловых центрах мира, сеть «Шератон» разработала программу «Гостиницы в аэропортах» в девяти европейских и четырех американских аэропортах. Эта инновационная программа содержит в себе «Кухню по биологическим часам», исследованную лучшими шеф-поварами сети и ведущими диетологами для того, чтобы преодолеть отрицательные эффекты от перелетов. «Номера для отдыха днем», которые можно забронировать за половину цены, при этом воспользовавшись теми же удобствами, что и во время проживания в отеле. Помимо этого, клиентам предоставляется набор «Transit Survival Kit», в который входят предметы личного пользования, и, конечно, услуги прачечной и химчистки.

Также, одним из новшеств стало управление электричеством. Подача электроэнергии в номер прекращается, когда карточку достают из специальной ниши. Это позволяет не только экономить, но и предотвращать пожары, порчу техники, которые могут возникнуть из-за невнимательности отдыхающих. Для пользователей IPhone разработано специальное приложение, позволяющее открывать двери номера. Полезны и специальные зеркала, транслирующие прогноз погоды. Они позволяют туристам одеться в подходящие вещи, не используя для этого интернет и не выходя на улицу.

Таким образом, развитие гостиничного бизнеса в мире невозможно без развития и внедрения инноваций. И, соответственно, гостиничный бизнес Казахстана не исключение.

Цель исследования: проанализировать развитие гостиничного бизнеса в Казахстане за последние годы и оценить внедрение современных инновационных подходов в практику казахстанских гостиниц.

Материалы и методы. Основу исследования составляют фактические данные о результатах деятельности гостиниц по данным Комитета по статистике Министерства национальной экономики Республики Казахстан [1]. Методы исследования: статистический, логический, экономико-математические методы.

Результаты исследования. Современные требования времени сегодня оказывают влияние на развитие казахстанских гостиниц. По оценкам ЮНВТО Республика Казахстан может принимать до 40 миллионов иностранных туристов в год, что в 3 раза больше, чем на сегодняшний день. Туристов, прибывающих в Казахстан, с каждым годом становится все больше и больше, соответственно количество посетителей гостиниц увеличивается с каждым годом. Динамика количества обслуженных посетителей в местах размещения с 2015 по 2018 годы показана в таблице 1.

Таблица 1. Количество обслуженных посетителей в местах размещения [1]

\begin{tabular}{|c|c|c|c|c|c|c|c|}
\hline & 2015 & 2016 & 2017 & 2018 & & & \\
\hline Регионы Казахстана & $\begin{array}{l}\text { январь- } \\
\text { декабрь }\end{array}$ & $\begin{array}{l}\text { январь- } \\
\text { декабрь }\end{array}$ & $\begin{array}{l}\text { январь- } \\
\text { декабрь }\end{array}$ & $\begin{array}{c}\text { январь- } \\
\text { сентябрь }\end{array}$ & $\begin{array}{c}2016 \text { к } \\
2015 \text { в \% }\end{array}$ & $\begin{array}{c}2017 \text { к } \\
2015 \text { в \% }\end{array}$ & $\begin{array}{c}2018 \text { к } \\
2015 \text { в \% }\end{array}$ \\
\hline Республика Казахстан & 3802225 & 4217782 & 5279406 & 4262963 & 110,9 & 138,9 & 112,1 \\
\hline Акмолинская & 226190 & 300439 & 341399 & 270002 & 132,8 & 150,9 & 119,4 \\
\hline Актюбинская & 83589 & 84744 & 100450 & 90415 & 101,4 & 120,2 & 108,2 \\
\hline Алматинская & 264819 & 435239 & 703663 & 721398 & 164,4 & 265,7 & 272,4 \\
\hline Атырауская & 211756 & 200003 & 184353 & 150787 & 94,4 & 87,1 & 71,2 \\
\hline Западно-Казахстанская & 94461 & 86868 & 112321 & 74090 & 92,0 & 118,9 & 78,4 \\
\hline Жамбылская & 93669 & 90776 & 103912 & 84917 & 96,9 & 110,9 & 90,7 \\
\hline Карагандинская & 258915 & 241260 & 292509 & 212572 & 93,2 & 113,0 & 82,1 \\
\hline Костанайская & 161259 & 146590 & 192174 & 155571 & 90,9 & 119,2 & 96,5 \\
\hline Кызылординская & 39373 & 49485 & 59192 & 42815 & 125,7 & 150,3 & 108,7 \\
\hline Мангистауская & 176068 & 192081 & 205904 & 191797 & 109,1 & 116,9 & 108,9 \\
\hline Туркестанская (ЮКО) & 144560 & 198515 & 269974 & 117307 & 137,3 & 186,8 & 81,1 \\
\hline Павлодарская & 110456 & 114057 & 147485 & 113664 & 103,3 & 133,5 & 102,9 \\
\hline Северо-Казахстанская & 68213 & 91016 & 120847 & 105016 & 133,4 & 177,2 & 154,0 \\
\hline Восточно-Казахстанская & 424336 & 460878 & 486157 & 462897 & 108,6 & 114,6 & 109,1 \\
\hline г.Нур-Султан & 722832 & 732764 & 989205 & 557127 & 101,4 & 136,9 & 77,1 \\
\hline г.Алматы & 721729 & 793067 & 969861 & 786795 & 109,9 & 134,4 & 109,0 \\
\hline г.Шымкент & - & - & - & 125793 & - & - & - \\
\hline
\end{tabular}


Данные таблицы 1 свидетельствуют, что за анализируемый период по количеству обслуженных клиентов лидирует Алматинская область, она за 2017 год обслужила на 165,7\%, а за 9 месяцев 2018 года - на 172,4\% больше гостей, по сравнению с 2015 годом. В ряде областей, таких как, Акмолинская, Кызылординская, Северо-Казахстанская, Туркестанская (ЮКО) также наблюдается рост количества обслуженных посетителей выше общереспубликанского значения.

Такая положительная динамика по количеству обслуженных клиентов не могла не найти отражение в изменении количества самих мест размещений в Республике Казахстан, что показано в таблице 2 .

Таблица 2. Количество мест размещений [1]

\begin{tabular}{|c|c|c|c|c|c|c|c|}
\hline & 2015 & 2016 & 2017 & 2018 & 2016 к & 2017 к & 2018 к \\
\hline Регионы Казахстана & $\begin{array}{l}\text { январь- } \\
\text { декабрь }\end{array}$ & $\begin{array}{l}\text { январь- } \\
\text { декабрь }\end{array}$ & $\begin{array}{l}\text { январь- } \\
\text { декабрь }\end{array}$ & $\begin{array}{c}\text { январь- } \\
\text { сентябрь }\end{array}$ & $\begin{array}{c}2015 \text { в } \\
\%\end{array}$ & $\begin{array}{c}2015 \text { в } \\
\%\end{array}$ & $\begin{array}{c}2015 \text { в } \\
\%\end{array}$ \\
\hline Республика Казахстан & 2338 & 2754 & 2987 & 3345 & 117,8 & 127,8 & 143,1 \\
\hline Акмолинская & 319 & 292 & 281 & 356 & 91,5 & 88,1 & 111,6 \\
\hline Актюбинская & 70 & 86 & 98 & 103 & 122,9 & 140,0 & 147,1 \\
\hline Алматинская & 306 & 400 & 449 & 518 & 130,7 & 146,7 & 169,3 \\
\hline Атырауская & 65 & 75 & 85 & 93 & 115,4 & 130,8 & 143,1 \\
\hline Западно-Казахстанская & 58 & 68 & 72 & 87 & 117,2 & 124,1 & 150,0 \\
\hline Жамбылская & 126 & 146 & 154 & 168 & 115,9 & 122,2 & 133,3 \\
\hline Карагандинская & 208 & 225 & 232 & 244 & 108,2 & 111,5 & 117,3 \\
\hline Костанайская & 107 & 111 & 119 & 134 & 103,7 & 111,2 & 125,2 \\
\hline Кызылординская & 75 & 90 & 90 & 93 & 120,0 & 120,0 & 124,0 \\
\hline Мангистауская & 63 & 83 & 78 & 80 & 131,7 & 123,8 & 127,0 \\
\hline Туркестанская (ЮКО) & 131 & 177 & 224 & 142 & 135,1 & 171,0 & 108,4 \\
\hline Павлодарская & 78 & 101 & 97 & 101 & 129,5 & 124,4 & 129,5 \\
\hline Северо-Казахстанская & 66 & 91 & 101 & 109 & 137,9 & 153,0 & 165,2 \\
\hline Восточно-Казахстанская & 371 & 455 & 505 & 538 & 122,6 & 136,1 & 145,0 \\
\hline г.Нур-Султан & 160 & 194 & 218 & 209 & 121,3 & 136,3 & 130,6 \\
\hline г.Алматы & 135 & 160 & 184 & 265 & 118,5 & 136,3 & 196,3 \\
\hline г.Шымкент & - & - & - & 105 & - & - & - \\
\hline
\end{tabular}

По данным таблицы 2 видно, что за последние три года наметилось увеличение количества мест размещений в Республике Казахстан с 2338 в 2015 году до 3345 за 9 месяцев 2018 года, таким образом прирост составил 43,1 \%. В целом такая же положительная тенденция сохраняется и в разрезе областей Казахстана. К регионам, которые увеличили свои показатели выше общереспубликанского значения относятся: Актюбинская, Алматинская, Туркестанская (ЮКО), Северо-Казахстанская, Восточно-Казахстанская области, а также города Нур-Султан, Алматы.

Однако, следует отметить, что возможности гостиниц намного шире, чем они их используют на практике. При большой способности загрузки, большинство гостиниц не могут заполнить даже 30-35\% номерного фонда. Об этом свидетельствуют нижеприведенные данные.

Таблица 3. Показатель заполняемости номеров, \% [1]

\begin{tabular}{|l|c|c|c|c|c|c|c|}
\hline & 2015 & 2016 & 2017 & 2018 & & \\
\cline { 2 - 7 } Регионы Казахстана & $\begin{array}{c}\text { январь- } \\
\text { декабрь }\end{array}$ & $\begin{array}{c}\text { январь- } \\
\text { декабрь }\end{array}$ & $\begin{array}{c}\text { январь- } \\
\text { декабрь }\end{array}$ & $\begin{array}{c}\text { январь- } \\
\text { сентябрь }\end{array}$ & $\begin{array}{c}2016 \text { к } \\
2015\end{array}$ & $\begin{array}{c}2017 \text { к } \\
2015\end{array}$ & $\begin{array}{c}2018 \text { к } \\
2015\end{array}$ \\
\hline 1 & 2 & 3 & 4 & 5 & 6 & 7 & 8 \\
\hline Республика Казахстан & $\mathbf{2 2 , 8}$ & $\mathbf{2 2 , 7}$ & $\mathbf{2 5 , 0}$ & $\mathbf{2 2 , 8}$ & $\mathbf{9 9 , 6}$ & $\mathbf{1 0 9 , 6}$ & $\mathbf{1 0 0 , 0}$ \\
\hline Акмолинская & 13,3 & 16,8 & 17,4 & 15,3 & 126,3 & 130,8 & 115,0 \\
\hline Актюбинская & 19,9 & 20,2 & 20,3 & 20,3 & 101,5 & 102,0 & 102,0 \\
\hline Алматинская & 20,4 & 19,3 & 19,7 & 18,7 & 94,6 & 96,6 & 91,7 \\
\hline Атырауская & 28,0 & 27,7 & 26,7 & 26,4 & 98,9 & 95,4 & 94,3 \\
\hline Западно-Казахстанская & 31,8 & 31,4 & 33,4 & 31,4 & 98,7 & 105,0 & 98,7 \\
\hline Жамбылская & 17,9 & 15,7 & 17,0 & 18,7 & 87,7 & 95,0 & 104,5 \\
\hline Карагандинская & 20,5 & 17,6 & 17,8 & 20,3 & 85,9 & 86,8 & 99,0 \\
\hline
\end{tabular}


Продолжение таблицы 3.

\begin{tabular}{|l|c|c|c|c|c|c|c|}
\hline \multicolumn{1}{|c|}{1} & 2 & 3 & 4 & 5 & 6 & 7 & 8 \\
\hline Костанайская & 21,9 & 21,1 & 28,4 & 28,1 & 96,3 & 129,7 & 128,3 \\
\hline Кызылординская & 18,9 & 18,3 & 20,7 & 17,0 & 96,8 & 109,5 & 89,9 \\
\hline Мангистауская & 28,2 & 20,7 & 21,8 & 26,1 & 73,4 & 77,3 & 92,6 \\
\hline Туркестанская (ЮКО) & 16,8 & 17,5 & 19,7 & 19,0 & 104,2 & 117,3 & 113,1 \\
\hline Павлодарская & 26,0 & 20,6 & 27,2 & 24,8 & 79,2 & 104,6 & 95,4 \\
\hline Северо-Казахстанская & 25,3 & 21,4 & 25,4 & 26,5 & 84,6 & 100,4 & 104,7 \\
\hline Восточно-Казахстанская & 26,1 & 25,3 & 24,7 & 28,5 & 96,9 & 94,6 & 1092 \\
\hline г.Нур-Султан & 25,1 & 27,9 & 31,4 & 19,5 & 111,2 & 125,1 & 77,7 \\
\hline г.Алматы & 26,3 & 26,3 & 29,8 & 29,2 & 100,0 & 113,3 & 111,0 \\
\hline г.Шымкент & - & - & - & 19,7 & - & - & - \\
\hline
\end{tabular}

На основании данных таблицы 3 видно, что общереспубликанский показатель заполняемости номеров увеличился с 22, 8\% в 2015 году до 25\% в 2017 году. В таких областях как Атырауская, Западно-Казахстанская, Костанайская, Павлодарская, Северо-Казахстанская, Восточно-Казахстанская и в городах Нур-Султан, Алматы наблюдается увеличение показателя заполняемости номеров выше общереспубликанского значения. Самый высокий уровень заполняемости номеров в городах Нур-Султан - 31,4\% и Алматы - 29,8\% в 2017 году.

При этом в ряде областей наблюдается заполняемость номеров ниже общереспубликанского показателя - Акмолинская, Актюбинская, Алматинская, Жамбылская, Карагандинская, Кызылординская, Мангистауская, Туркестанская (ЮКО).

Еще одним показателем развития гостиничного бизнеса, является объем оказанных услуг, который приведен в таблице 4.

Таблица 4. Объем оказанных услуг, тыс. тенге [1]

\begin{tabular}{|c|c|c|c|c|c|c|c|}
\hline \multirow[b]{2}{*}{ Регионы Казахстана } & 2015 & 2016 & 2017 & 2018 & \multirow{2}{*}{$\begin{array}{c}2016 \text { к } \\
2015 \text { в } \\
\%\end{array}$} & \multirow{2}{*}{$\begin{array}{c}2017 \text { к } \\
2015 \text { в } \\
\%\end{array}$} & \multirow{2}{*}{$\begin{array}{c}2018 \text { к } \\
2015 \text { в } \\
\%\end{array}$} \\
\hline & $\begin{array}{l}\text { январь- } \\
\text { декабрь }\end{array}$ & $\begin{array}{l}\text { январь- } \\
\text { декабрь }\end{array}$ & $\begin{array}{l}\text { январь- } \\
\text { декабрь }\end{array}$ & $\begin{array}{c}\text { январь- } \\
\text { сентябрь }\end{array}$ & & & \\
\hline Республика Казахстан & 72597228,3 & 82853434,6 & 108359760,4 & 78938789,7 & 114,1 & 149,3 & 108,7 \\
\hline Акм & 4255885,7 & 5020856,3 & 5656946,1 & 5028 & 18,0 & & \\
\hline Акт & 1445833,9 & 1549764,0 & $2078^{\prime}$ & 1532 & 7,2 & & 06,0 \\
\hline Алм & 32028 & 47794 & 8280 & 8686 & 9,2 & & 271,2 \\
\hline Аты & $6802^{\prime}$ & 7086 & 7192 & 5778 & 4,2 & & 84,9 \\
\hline Запа & 1970 & 2906 & 312 & 2000 & 47,5 & & 101,5 \\
\hline ЖаN & 8748 & 1004 & 1258 & 112 & 14,8 & 3,8 & 128,0 \\
\hline Kap & 3418 & 387 & 4226 & 317 & 3,3 & 3,6 & \\
\hline & 1075 & 1122 & 1506 & 132 & 04,4 &, 1 & 123,0 \\
\hline & & & & & 5,0 & 5,3 & 9,8 \\
\hline & & & & & & & 85,0 \\
\hline & & & & & 6 & & \\
\hline & & & & & & & 4 \\
\hline & & & & & & & \\
\hline & 3290 & 3877 & 4278 & $484 \mathrm{C}$ & 9 & & 47,4 \\
\hline & & & & & & & 90 \\
\hline & 18587043,8 & 19662212,0 & 4696845,7 & 1838 & 105,8 & 25,3 & 98,9 \\
\hline г.Шымкент & & & - & 2423180,2 & & & \\
\hline
\end{tabular}

Согласно данным таблицы 4 в 2017 году объем оказанных услуг по сравнению с 2015 годом по Казахстану увеличился на 49,3\% и составил 108359760,4 тыс. тенге. Сохраняется положительная тенденция увеличения объема оказанных услуг и в разрезе областей Казахстана за исключением Мангистауской области.

Выводы. В заключении отметим, что полученные результаты исследования подтверждают, что развитие гостиничного бизнеса Казахстана идет по положительной траектории. Это подтверждают статистические данные о состоянии гостиниц в республике за последние годы. Соответственно, чем больше и быстрее начнут внедряться новые технологии в сферу туризма и гостиничного бизнеса, тем быстрее Казахстан сможет конкурировать на мировом рынке. 
Однако следует отметить, что основу гостиничного сектора Казахстана составляют в основном небольшие гостиницы, при этом они преимущественно не имеют «звезд». Присвоение обязательной «звездности» гостиницам предлагает Ассоциация гостиничного и ресторанного бизнеса Республики Казахстан. В 2017 году около 84\% гостиниц Казахстана не имело звёздности. Данный факт означает, что оснащенность их номеров заметно хуже, если сравнивать с зарубежными гостиницами.

Больших и по-современному развитых гостиниц не так уж много, к сожалению, у нас в стране. Хотя крупные гостиницы лучше оснащены технологиями, так как нацелены на более состоятельных клиентов. Вместе с тем, использование новых технологий значительно повышает стоимость номеров, но в тоже время, их использование делает отдых туриста намного комфортнее. Городами «гигантами» в гостиничной сфере Казахстана принято считать города Алматы и Нур-Султан. Два самых крупных и значимых города Республики, именно в этих городах, находят применение современные технологии в гостиничном бизнесе. Наиболее широко используемые инновационные подходы к развитию гостиничного бизнеса в Республике Казахстан представлены на рисунке 2.

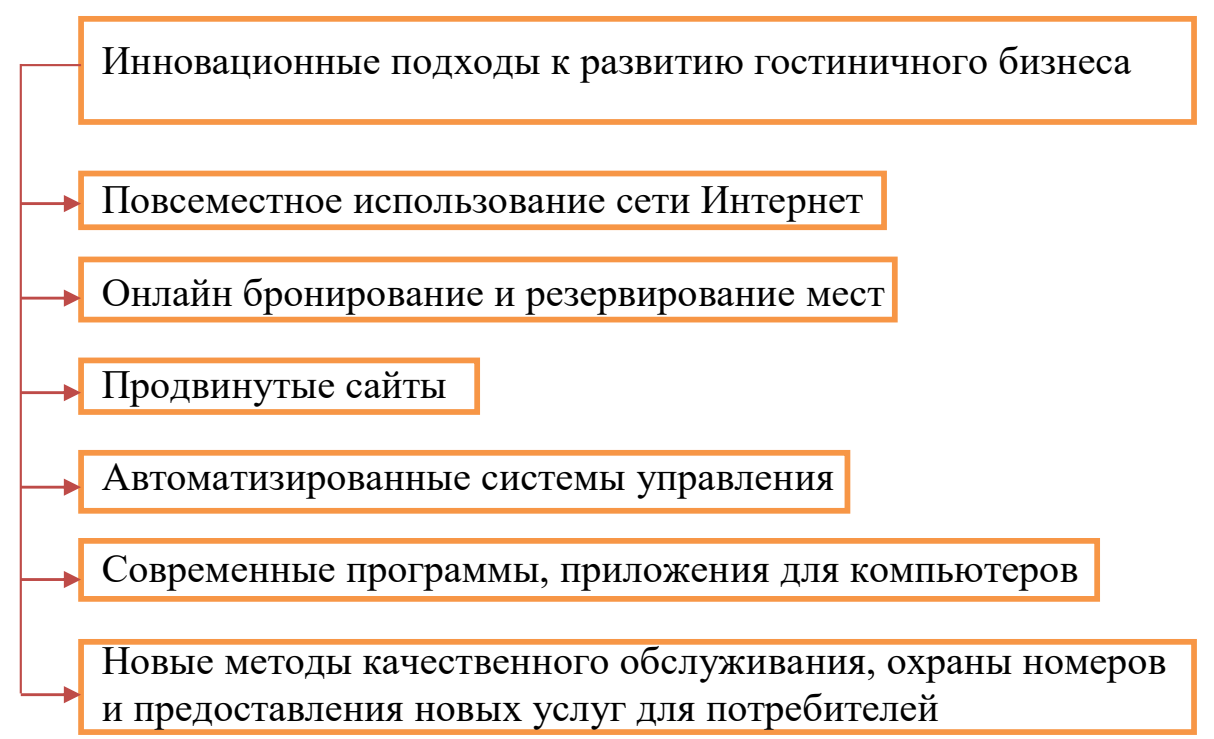

Рис. 2. Инновационные подходы к развитию гостиничного бизнеса РК

Таким образом, внедрение современных технологий инновационного характера в гостиницы Казахстана происходит медленно, не так как хотелось бы потребителям и самим гостиницам. Тем не менее, радует появление на нашем рынке таких крупных гостиничных сетей как Marriott, Hilton Garden Inn и Ritz-Carlton. Надеемся, что опыт успешных гостиниц подхватят и все остальные участники данного рынка услуг.

\section{ЛИТЕРАТУРА}

1. Сайт Комитета по статистике Министерства национальной экономики Республики Казахстан: Электронный ресурс. Режим доступа: http://stat.gov.kz

2. 10 новых технологий для гостиничных номеров. От умных термостатов до роботов на стойке регистрации. Тренды отельной автоматизации. Электронный ресурс. Режим доступа: https://hotelier.pro/use/item/2150-smart

3. Обзор рынка гостиничного бизнеса Казахстана и России. Электронный ресурс. Режим доступа: https://forbes.kz/finances/markets/chem_otlchiaetsya_gostinichnyiy_biznes_kazahstana_ot_rossiyskogo/ 